\title{
Beninese therapeutic pluralism. Historical roots and bioethical issues
}

\author{
A Maccaro ${ }^{1,2}$ \\ ${ }^{1}$ PhD Philosophical Sciences, Humanities Department - University of Naples Federico II \\ ${ }^{2}$ Post- doc Social Sciences Department - University of Naples Federico II
}

submitted: Aug 4, 2018, accepted: Dec 3, 2018, EPub Ahead of Print: Dec 9, 2018, published: Jul 7, 2019

Conflict of interest: None

DOI: 10.24019/jtavr.53 - Corresponding author:Dr. Alessia Maccaro, alessia.maccaro@gmail.com

(C) 2018 Fondazione Vasculab impresa sociale ONLUS. All rights reserved.

\begin{abstract}
Retracing the history of the spread of modern medicine in the former Kingdom of Dahomey, now the Republic of Bénin (sub-Saharan Western Africa), aims to provide a peculiar perspective of colonial domination that, as well known, has dramatically passed through the form of controlling bodies that is not wrong to define as "biopolitical". The aim of the essay is attempting to show how the gesture aimed at trampling the cultural identity of the people of Benin. Passing through the denial of traditional therapeutic culture - which is disregarded, as to this day the primary medical reference remains that of traditional medicine - re-proposes itself in forms that are apparently opposites in the attempt, only theoretical, of contemporary politics to recover and defend the local
\end{abstract}

\section{Introduction}

The progressive affirmation of Western medical knowledge in Africa has been throughout history, as well known, an indispensable instrument of colonial domination. The deposition of traditional medical knowledge of African populations, especially therapeutic one, has been for long time a way of underestimating the cultural identity of a group and of imposing Western domination.

In fact, cultural difference has often been used to legitimate the strongest power, under the name of "mission", in order to impose its own identity, assumed ideologically as superior and, therefore, to discipline other people life without any guarantee of explicitly established rules (biopolitics) (Rodotà, $2006^{1}$ ).

On closer inspection, however, the bad habit of the phenomenon of assimilation, which in return of therapeutic tradition, conjecturing hypothetical forms of peaceful and equal coexistence between traditional and modern medicine. The angle of intercultural bioethics, far from the long-standing multiculturalism, will allow us to have a glimpse into the emerging ethical-political dilemmas regarding this issue, as well as underline how the defense of therapeutic traditions, ascribable to the right of cultural identity, represents a form of guarantee of the human and of his rights. A true "white man's burden", to consider responsibly in the perspective of an inclusive citizenship, on which in today's times it's urgent to reflect upon. bioethics

Keywords traditional medicine, voodoo, Bénin, "citizenship" - that means availability, in this case, of modern medical and scientific knowledge, as well as of rights and morals -, calls for the renunciation of cultural identity, seems to be experienced again in the contemporary phenomenon of emancipation.

In fact, the longed-for emancipation through rights as antidotes to violence is in some way a request to populations to tend to a universal model and, therefore, to renounce to their own culture, which is their identity, in order to become citizens.

Nevertheless, as we shall see, the universality of rights, in particular of human rights referred to, is not exclusive but inclusive, and asks people not to renounce to their diversity, which is their specificity, but to preserve it in order to create horizons, where sharing is an option. 
1

Very well renowned is the closure manifested by the European powers in the colonial era towards the colonized cultures and their traditions, above all therapeutic ones. This attitude was leaning on the Eurocentric conviction of knowledge inconsistency of the indigenous populations who were simplistically dismissed as magical and superstitious practitioners. Such an attitude had the indirect aim of weakening the social, religious and even political role of healers, disliked by the colonizers (Arnold, $1988^{2}$ ). Moreover the colonial empires engaged in an ideological diffusion of the indigenous body as wild, impure, sick, bearer of physical and moral contagion, which had to be saved. Thus began the slow and inexorable affirmation of rationalized, modern, western, scientific biomedicine, as of today mostly defined as "conventional" which, through the derision, reduction and denial of the other people's culture, presented itself as a civilizing mission of the colonized population, the burden of white man (Kipling, 1899 ${ }^{3}$ ) and his essential moral obligation (Marks, $\left.1997^{4}\right)$.

This is how the biopolitical control of the other began (Foucault, 2005 ${ }^{5}$ ), also passing through the missionary medicine with specific laws about it. A strict legislation was imposed to all the colonies regarding healthcare policy. This legislation was oriented to a massive construction of infrastructures (hospitals, dispensaries, pharmacies) which, inevitably, led to a weakening of the role of traditional therapists who were shortly forced to operate under illegal conditions (Comaroff, $1993^{6}$ ).

In the aftermath of independence, in the second half of the twentieth century, the situation of the former colonies did not change much. The main efforts of the new African governments were aimed at strengthening the existing health infrastructures and, at most, improving hygiene, by addressing these interventions to propaganda campaigns purposes. Equally oriented to the affirmation of modern medicine were the interventions of international organizations, mainly of the WHO and of the organizations that were involved in aid projects and international cooperation: a new form of colonialism was arising, always moved by the awareness of exclusive possession of the

\section{2}

When the WHO requested to enhance traditional medicine, the Bénin, a Sub-Saharan West African country, responded positively right from the start [1]. After independence in 1960, it experienced a long twenty-year Marxist-Leninist government led by General Kérekou in which, for ideological nature reasons, much emphasis was knowledge and technical skills of the West which imposed its supremacy (Bernardi, 1998, p. $21^{7}$ ).

Although government actions tended to agree to the diffusion of modern medicine, in the various African states there were discordant and unclear attitudes towards traditional therapeutic practices that went from the clean refusal of a legislative recognition to the informal approval of traditional therapists, until the official recognition of healers' role that, however, did not clearly regulate the areas of intervention permitted to them, as in Bénin's case.

What is certain is that around the mid-70s there was a general change in the consideration of tribal therapeutic practices, certainly accelerated by the official recognition of traditional African medicine by the WHO, which in 1976 defined it as:

«Traditional medicine has a long history. It is the sum of knowledge, skills, and practices based on theories, beliefs, and experiences indigenous to different cultures, as explicable or not, as well as used in the maintenance of health as well as in the prevention, diagnosis, improvement or treatment of physical and mental illness» ${ }^{8}$.

Subsequently, in 1978, a declaration was issued by the WHO in Alma Ata in Kazakhstan recommending member countries to promote and prefer the use of traditional medicine, especially in those areas where it was recognized as Primary Health Care (PHC), through the implementation of health programs that involved interacting with biomedicine 9 . The main idea of this proposal was that traditional medicine, with its widespread diffusion on the territory, could somehow meet the deficiencies of the official health system ${ }^{10}$, above all the almost impossible accessibility due both to costs, too expensive even for an African employee, and to locations of hospitals. They are in fact, concentrated only in urban areas, despite the majority of the African population is residing, and still resides, in rural areas. This recovery of traditions was then endorsed by the same African politicians who persuaded themselves that supporting the endogenous resources with nationalistic ideological intentions could represent a resource that could be spent on the level of political consensus, which, moreover, perfectly matches with the calculations of pharmaceutical companies.

placed on the enhancement of traditional, even medical, culture (Dozon, $1987^{11}$ ).

Here, therefore, the work of integration between traditional and modern medicine was undertaken promptly, encouraging the inclusion of western health workers in rural Beninese villages. However, even though they had received 
the task of making themselves available for the knowledge of traditional practices with the aim of seeking forms of mediation and exchange with modern medical knowledge, in fact they limited themselves to transmitting the rudiments of basic health care to the healers and women in the role of midwives. This clearly suggests how the control matrix - ex. of the births - of colonial mold was prevailing against the, although proclaimed, enhancement of traditional medicine.

Moreover, integration was not limited to the action of doctors in tribal communities, but also included the introduction of traditional therapists, mostly voluntary, in official health facilities where not only they could continue to learn notions of prevention and hygiene to be spread in the villages, but they would also have practiced their art by offering care services. In fact, in some local hospitals, as in the central hospital of the Borgou province, in 1984 volunteer healers were selected, by Beninese doctors, to put their skills at disposal of patients who could have been given traditional treatments under the supervision of hospital doctors. However, the experience turned out to be a total failure, since only two years later only one healer remained to offer his free consultations in the hospital, hoping to be officially included in the medical group.

The Beninese case immediately expresses one of the basic problems of integration projects between traditional and modern medicine, that is the one related to the role assigned to healers, mostly compared to that of a nurse or paramedical staff, rather than that of a therapist to whom is recognized the possession of an effective and autonomous knowledge (Green, 1988 ${ }^{12}$ ). In fact, the conventional medical staff has shown certain diffidence towards traditional therapists, due to the difficulty of accepting unorthodox medical practices (WHO, 1984 ${ }^{13}$ ). Traditional medicine thus has come to fill the void of modern medicine, reducing itself to basic health care with a prevalent purpose of popularizing the principles of hygiene and the importance of vaccines, which certainly has had its advantages, but fails to do justice to what it really represents.

With respect to this attitude, traditional healers in some circumstances were reluctant to accept the subordinate role that they wanted to impose them and showed a disinterest or refusal regarding possible collaborations with modern medicine, in other cases instead they show a clear willingness to cooperate. After all, the institutional recognition and inclusion in the official medical structure could not only lead to an increase in social prestige, and sometimes economic advantages, but could

\section{3}

It is indeed evident that the clear division between traditional medicine of a more herbalist nature and the also respond to the desire of healers to improve their skills, through the acquisition of new knowledge (Beinart-BrownGilfoyle, $2009^{14}$ ).

The process of professionalization of indigenous medicine, however, has involved a renegotiation of social roles, a redefinition of hierarchies, to which the leading cadres of official health were not always ready (LastChavunduka, $1986^{15}$ ).

Bénin once again exemplifies this collaboration between modern medicine and physiotherapeutic traditions. Even nowadays, in fact, more than $80 \%$ of the Beninese population (WHO, 2002) uses traditional natural medicine to treat disease, since «in a context in which HIV, malaria, tuberculosis and many others diseases are the major concerns of public health and development, traditional medical knowledge and practices can be solutions to very complex problems related to taking care of the disease» ${ }^{16}$.

With this in mindset, even if traditional medicine is not yet fully integrated into the national health system, the Beninese Ministry of Health has implemented a Programme National de la Pharmacopée et de la Médicine Traditionnelles which, in addition to offering a regulatory framework, proposes a code of ethics and conduct for the practice of traditional natural medicine and makes possible nowadays «the production in commercial quantities of standardized traditional medicines, in order to integrate traditional medicine into the national health system ${ }^{17}$.

However, as we read from the Code d'Éthique des Praticiens de la Médicine Traditionnelle, healers must keep away from the practices of conventional medicine, they cannot use modern technical tools and cannot present themselves as doctors or professors ${ }^{18}$. So, expropriated by the spiritual character of their traditional role and unable to approach a modern role, they remain in an unclear limbo: obliged to reveal the composition of their effective medicines ${ }^{19}$, but not authorized to learn and use new ones. In fact, on closer inspection, the idea of rationalizing traditional medicine through the study of medical plants used by healers, although it may seem a real form of opening to cultural mentality and an appropriate form of integration, in fact it leans on a prejudicial attitude. The traditional practices are in fact evaluated and judged on the basis of Western scientific criteria, which, besides reiterating the primacy of Western scientificity, conceals a continuing will to control the activities of traditional therapists.

traditional medicine that is more tending to a spiritual/ supernatural sphere is mostly artificial and is a further 
forced attempt to understand traditional medicine according to criteria that are familiar to the modern mentality. Healers, in fact, move between the two areas, resorting, according to the case, to herbalist or spiritual practices, but also the former ones share the same symbolic set of spiritual ones and it is therefore difficult to isolate the aspects that can be scientifically analyzed without changing the horizon of meaning in which they move.

Traditional medicine, as it is known, responds to the cultural systems from which it arises and does not limit the disease to the simple biological event alone, but intends it through a holistic, global approach and, therefore, is able to give an overall response to an uneasiness that is at the same time biological, existential, social and cultural (Eisenberg, 1977, p. $11^{20}$ ).

Therefore up to now, rather than the real integration between the two models of traditional and modern medicine, there has been an attempt by official medicalhealth institutions to bend the ideological models and traditional therapeutic practices to the scientific paradigms, denying the magical-religious configurations of symbolic systems to which those practices are closely linked. And this, evidently, implements a real reduction rather than an enhancement of traditional knowledge.

This attitude is certainly a legacy of imperialism which, by operating indirect control over political elites, is the backbone of the forms of neocolonialism that belong to our era [2]. In fact, the process of modernization, by advancing inexorably, has expanded in a way that marginalize the traditional system. Such system, in order to exist, must deny itself in its overall essence and show only that quantum that is able to the "normalization", which can only lead to the progressive disappearance of tradition.

In this way, different and extremely delicate questions arise: on one hand it is clear that modern medicine, being the one whose efficacy is most proven, should spread without limits in order to guarantee everyone the right to adequate medical treatment and the right to healthcare; on the other hand, in order for these rights to be guaranteed, each individual should be put in the position to benefit from it, which means, therefore, reviewing the problems of access to health care and free treatments of the health system, which are still dramatically unsolved in Africa. However, the fact that the importance of the global diffusion of biomedicine is not questionable does not imply that such modernization should stifle or distort traditional medicine, not only because this is an act of violence against the cultural identities that derive from it, but also because this would mean to deny the value not only cultural, but also curative of traditional practices.

Once again, the dilemma regarding the modalities of integration between traditional and modern medicine, becomes more and more decisive in the measure in which it seems impossible to speak of integration without distorting the first system of care or presenting the second as an imposition. The real problem is that not only it is difficult to talk about integration, but we should probably also ask ourselves whether it is indeed desirable an integration considering that inevitably leads to the loss of identity of tradition.

In fact, all the national and international maps reaffirm the indispensability of respect for traditions, which not only pertains to the sphere of freedom - understood as freedom of conscience and worship - but is a fundamental and inalienable right of every individual or group that is a duty of the states to guarantee. As stated in art. 17 paragraphs 3 the African Charter of Human and People's Rights composed of the Organization de l'Unite Africaine (OAU) in 1981 and ratified by Bénin on January 20, 1986: «The promotion and protection of morals of traditional values community shall be the duty of the State» ${ }^{21}$.

It is therefore evident that it is impossible for the traditions to be swallowed up in the process - even if necessary - for the diffusion of modern medicine. However, since integration does not always mean restitution of dignity and enhancement of indigenous traditions, but, paradoxically it can contribute to their distortion and their disappearance, we must re-discuss the concept of integration since, full as it is of stereotypes and prejudices, is operationally impractical (Benoist, 1989²2; DozonSindzingre, $1986^{23}$ ). Probably more than integration we should be content with cooperation between two semantic universes that are different, but complementary, which must begin by providing a genuine recognition of traditional medicine as a whole, not claiming to separate only few technical aspects denying the theoretical foundations of the entire cultural system (Habermas - Taylor, 1998 ${ }^{24}$ ). Denying the recognition of cultural traditions, denying their dignity, is, in fact, a way of killing the other, his identity, that is no longer existent after the tragedies that history has witnessed which degraded the real meaning of human being and that memory would better hold back more firmly.

\section{4}

Bioethical reflection then becomes necessary to the extent that it appeals not only to morals, to medicine but 
traditions, which is a fundamental human right that has only been partially guaranteed until now.

In this regard the Universal Declaration of Bioethics and Human Rights, promoted by UNESCO in 2005, in art. 12 reads: «the importance of cultural diversity and pluralism should be given due regard. However, such considerations are not to be invoked to infringe upon human dignity, human rights and fundamental freedoms, nor upon the principles set out in this Declaration, nor to limit their scope» $^{25}$.

Therefore it seems to be possible to say that a genuine cooperation between complementary care systems is possible only after a genuine recognition of traditions, which must first be legislative. As mentioned, in fact, traditional medicine is practiced, tolerated and even partially regulated by ministerial documents, but it is not legislated. The health system, for its part, must show itself capable of recognizing in its complex the plural but not discordant souls that inhabit it: this will mean no longer imposing, but arranging the conditions to carry out a reform that invests the entire health structure, that should be oriented towards a decentralization of its own point of view as well as of the cure strategies to pursue.

In this way modern medicine will be able to get closer to culture and population, but on the other hand we must continue to bring traditional medicine closer to the rigor of science, taking into consideration not only the quantitative aspects, but also the qualitative ones of the conceptual and philosophical system at the base of this therapeutic approach.

From a practical point of view, decentralization will also imply that the two offers of care must be more present both in urban and rural areas: this means not only yearning for greater coverage of the national health system, but also preserving the presence of therapists in the area.

In this way, the real complementarities between the two therapeutic options can be manifested, which in

\section{Endnotes}

[1] It's been 15 years since Africa has been celebrating the day of traditional medicine, as proposed by the "Ouagadougou Resolution" on the Traditional Medicine (31 Aug 2000). Benin has been celebrating it under the auspices of the Ministère de la Santé, every 17th of November. During last meeting Prof. Roch Hougnihin, Coordinator of National Program of Pharmacopeia and Traditional Medicine underlined the importance of this day which is, according to him, a unique opportunity for taking stock of the situation related to traditional medicine in Benin, especially in relation to what concerns the knowledge transmitted by the ancestors, as well as the invaluable natural resources of the country. WHO Benin. Le Bénin a commémoré la 15ieme Journée Africaine de Médecine Traditionnelle, a certain sense increases the self-determination of the individual with respect to the choices of care, since the patients can decide to refer now to one now the other health reference always with the guarantee of the state on the validity - even before accessibility (Anyinam, $1987^{26}$ ), which is a different problem from the one examined - of both.

Therefore, regardless of the proposal of decentralized cooperation between traditional and modern medicine, what would seem to be no longer postponed in our society, that professes itself as pluralist, is a more convinced definition of ethical and political strategies that are genuinely capable of guaranteeing respect for therapeutic traditions and, at the same time, respect for the rights of care which also the former ones consist of. However, as we have seen, the protection of the traditional philosophical constructs of each population goes beyond the sanitary discourse and refers to the principles of identity, freedom and dignity, belonging to the list of fundamental human rights that cannot be circumvented by the overwhelming push of the modern, especially in those countries where the latter is not yet fully guaranteed.

Therefore if «under the title of third generation of human rights sometimes is included the right to cultural identity with its linked claims» (Kaufmann, 2009, p. $56^{27}$ ), the latter one, being part of the framework of human rights, is recognized as being inalienable and, therefore, not required to mediate - unless it endangers human rights themselves - or compromise with modernity. However, recognizing this is only the first step to rethink the question of the relationship among human rights and, above all, the duty of states to guarantee them in respect of social justice and human dignity, especially in relation to the so-called Third World countries and, in particular, to the health problem, becomes less and less possible to postpone (Nussbaum - Sen, $1993^{28}$ ).

2017: https://afro.who.int/fr/news/le-benin-commemore-la-15iemejournee-africaine-de-medecine-traditionnelle (nov. 2018).

[2] The studies of P. Hountondji on what he calls "mondialisation des savoirs" are particularly important in this regard, mainly because it creates a series of interpretative and epistemological difficulties especially, and above all, towards the theme of decolonization of African knowledge. As a matter of facts, the author shows how some African intellectuals, first supporters of an anticolonial policy, now justify the choices of governments and contemporary policies which, in fact, favor the diffusion of a dimension that is only partial to tradition. 


\section{References}

1) Rodotà S. La vita e le regole. Tra diritto e non diritto. Milano: Feltrinelli; 2006

2) Arnold D. Imperial Medicine and Indigenous societies. Manchester: Manchester University Press; 1988.

3) Kipling R. The White Man's Burden. McClure's Magazine. 1899 Feb 12

4) Marks S. What is colonial about colonial medicine? And what has happened to imperialism and health? Social History of Medicine. 1997 Aug 1; 10(2):205-219.

5) Foucault M. Nascita della biopolitica, (Collège de France 1978-1979). Milano: Feltrinelli; 2005.

6) Comaroff Je. The diseased heart of Africa. Medicine, colonialism and the black body. In: Lindenbaum S, Lock M, editors. Knowledge, power and practice. The anthropology of everyday life. Berkeley: University of California Press; 1993. p. 305-329.

7) Bernardi B. "Salute per tutti”: prospettiva XXI secolo. L'arco di Giano. Rivista di medical humanities. 1998;16:1-31.

8) WHO. Traditional, complementary and integrative medicine Available from http://www.who.int/traditional-complementaryintegrative-medicine/about/en/ at the date of Dec 4, 2018

9) International Conference on Primary Health Care (1978 Alma-Ata, USSR), World Health Organization \& UNICEF. (1978). Primary health care : report of the International Conference on Primary Health Care, Alma-Ata, USSR, 6-12 September 1978 / jointly sponsored by the World Health Organization and the United Nations Children's Fund. Geneva : World Health Organization. Available at the address http://www.who.int/iris/handle/10665/39228 at the date of Dec 8, 2018.

10) Kofi-Tsekpo M. Institutionalization of African traditional medicine in health care system in Africa. Afr $\mathrm{J}$ Health Sci. 2004;11(1-2):I-II.

11) Dozon J-P. Ce que valoriser la médicine traditionnelle veut dire. Politique Africaine. 1987;28:9-20.

12) Green EC. Can collaborate proper between biomedical and African indigenous health practitioners succed. Social Science and Medicine. 1988;27(11):1125-30

13) WHO. Traditional medicine and health care coverage. A reader for health administrators and practitioners. Geneva: WHO; 1984.

14) Beinart W, Brown K and Gilfoyle D. Experts and Expertise in Colonial Africa Reconsidered: Science and the Interpenetration of Knowledge. African Affairs. 2009 Jul;108(432):413-33.
15) Last M, Chavunduka GL, editors. The professionalization of African medicine. London: Routledge; 1986 (new ed. 2018).

16) Ministère de la Sante, Direction Nationale de la Sante Publique, République du Bénin, Programme national de la Pharmacopée et de la médicine traditionnelles (PNPMT), Manuel d'initiation des professionnels de la santé aux systèmes d'éducation et de transmission du savoir en Médicine Traditionnelle au Bénin, Cotonou: Janvier 2011:8.

17) Protocole de prise en charge du paludisme basé sur les pratiques traditionnelles efficaces au Bénin, Cotonou: Septembre 2009.

18) Code d'éthique des praticiens de la médicine traditionnelle: Loi $\mathrm{N}^{\circ}$ 2010/40 du 8 Decembre 2010, art. 31.

19) Mahomoodally MF. Traditional Medicines in Africa: An Appraisal of Ten Potent African Medicinal Plants. EvidenceBased Complementary and Alternative Medicine [Internet]. Hindawi Limited; 2013;2013:1-14. Available from: http:// dx.doi.org/10.1155/2013/617459

20) Eisenberg L. Disease and illness. Distinction between professional and popular ideas of sickness. Culture, Medicine and Psychiatry. 1977;1(1):9-23.

21) Constitution de la Republique du Bénin. Porto-Novo: Rogav; 2015.

22) Benoist J. Médecine traditionnelle et médecine moderne en République Populaire du Bénin. Écologie humaine, bulletin d'écologie humaine. 1989;7(1):84-9.

23) Dozon J-P, Sindzingre P. Pluralisme thérapeutique en médecine traditionnelle en Afrique contemporaine. Prévenir. 1986; (12):43-52.

24) Habermas J, Taylor C. Multiculturalismo. Lotte per il riconoscimento. Milano: Feltrinelli; 1998.

25) UNESCO. Universal Declaration of Bioethics and Human Rights. 2005. Available from http://www.unesco.org/new/en/socialand-human-sciences/themes/bioethics/bioethics-and-human-rights/ at the date of Dec 4, 2018.

26) Anyinam C. Availability, accessibility, accettability and adaptability: four attributes of african ethnomedicine. Social Science and Medicine. 1987;25(7):803-11.

27) Kaufmann M. Diritti umani. Napoli: Guida; 2009.

28) Nussbaum M, Sen A, editors. The Quality of Life: a Study Prepared for the World Institute for Development Economics Research of the United Nations University. Oxford: Clarendon Press; 1993. 